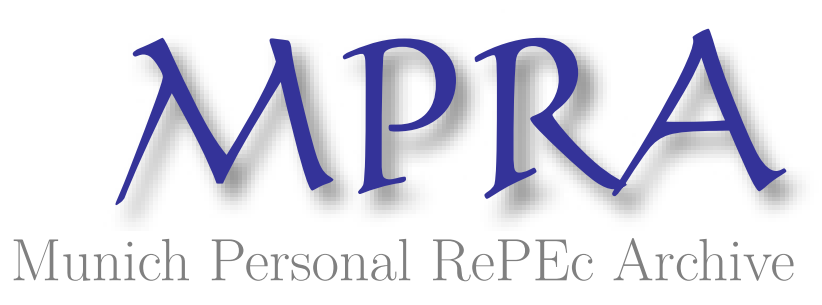

\title{
On the Efficiency of AC/DC: Bon Scott versus Brian Johnson
}

Oxoby, Robert

University of Calgary

7 May 2007

Online at https://mpra.ub.uni-muenchen.de/3196/

MPRA Paper No. 3196, posted 11 May 2007 UTC 


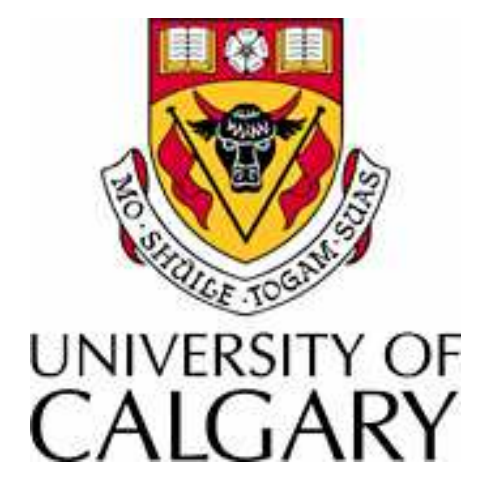

\title{
Department of Economics Discussion Paper 2007-08
}

\section{On the Efficiency of AC/DC: Bon Scott versus Brian Johnson*}

\author{
Robert J. Oxoby \\ Department of Economics \\ University of Calgary \\ Calgary, AB T2N 1N4
}

This paper can be downloaded without charge from

http://www.econ.ucalgary.ca/research/research.htm 


\title{
On the Efficiency of AC/DC: Bon Scott versus Brian Johnson
}

\author{
Robert J. Oxoby* \\ May 7, 2007
}

\section{Introduction}

The band AC/DC is considered one of the seminal hard rock bands, often compared to Led Zeppelin and Black Sabbath in influencing many subsequent hard rock and heavy metal bands. The band was formed in 1973 by Angus and Malcolm Young who took the band's moniker from the back of their sister's sewing machine. In its 35 year history, the band has sold more than 150 million albums, including 42 million copies of the 1980 album Back in Black, making Back in Black the highest selling album by any rock band. In 2003 the band was inducted into the Rock and Roll Hall of Fame. Given all this, it is no wonder that AC/DC has such a rabid fan base and, as discussed below, faces an epic debate regarding its line-up.

Among musicologists, researchers of popular culture, and rock and roll lovers of all ages there exists a common debate. That is, with respect to the rock band AC/DC, who is the better vocalist: Bon Scott or Brian Johnson? The band's original vocalist, Scott, performed on seven of the band's albums (excluding live albums and compilations), passing away in 1980. Brian Johnson joined the band in 1980, serving as vocalist on nine albums (excluding live albums and compilations). Since 1980, there has been near constant contention regarding who was the better singer.

In this paper, we explore this issue. Since it is difficult to ascertain which vocalist was better given the heterogeneity of musical tastes, our analysis does not focus on the aural or sonic quality of the vocalists' performances. Rather, using tools from the field of experimental economics, and we consider which vocalist results in individuals

${ }^{*}$ Department of Economics, University of Calgary, 2500 University, Drive NW, Calgary, AB Canada T2N1N4, tel: 403.220.2586, fax: 403.282.5262; email: oxoby@ucalgary.ca. 
arriving at more efficient outcomes in a simple bargaining game. Our results suggest that having participants listen to songs by AC/DC in which Brian Johnson served as vocalist results in participants realizing more efficient outcomes. Thus, in terms of a singer's ability to implement efficient behavioral outcomes among listeners, our results suggest that Brian Johnson was a better vocalist than Bon Scott.

\section{Experimental Design}

In our experiment we utilize a common procedure from experimental economics entitled the ultimatum game (see Roth, 1995). In this game, individuals are randomly paired and assigned the roles of either proposer or responder. Proposers are allocated a sum of money from which they must choose an amount to extend as an offer to the responder. The responder, upon learning of this offer, can either accept or reject the offer. If she accepts the offer, the responder receives the offer (in cash) and the proposer is given the original sum of money less the offer. If the offer is rejected, both participants received nothing. ${ }^{1}$

Under the assumption that individuals have preferences over only their own wealth, the predicted game theoretic outcome (the subgame perfect Nash equilibrium) is that in which the proposer extends the smallest possible offer and the responder (weakly) accepts any offer greater than (or equal to) zero. Such an outcome is efficient in the sense that no resources are lost in the outcome (i.e. the resources are not lost via a decision to reject the offer). However, research and experimental economics has shown that proposers typically offer between $20 \%$ and $50 \%$ of the wealth available in the experiment and responders, on average, reject offers below $30 \%$ (see Camerer, 2003a). These results suggest that individuals not only value their own wealth, but also the wealth of others and the fairness of an allocation. This has fostered new models of economic behavior incorporating inequity aversion, cooperation, and reciprocity (e.g., Bolton and Ockenfels, 2000; Charness and Rabin, 2002; Fehr and Schmidt, 1999).

In our experiment, participants were paired and were explained the structure of the game. Each pair was endowed with $\$ 10$ to use in the game (i.e. $\$ 10$ from which the proposer must choose an offer to extend the responder) and we restricted offers the integer values (i.e. whole dollars). Prior to learning their roles of proposers or responders, each participant provided the offer they would extend were they assigned

\footnotetext{
${ }^{1}$ Similar experiments have been utilized by deQuervain et al. (2004) and Camerer (2003b).
} 
the role of proposer and, for each possible offer (i.e. for each offer between zero and $\$ 10)$, whether they would accept or reject the offer were they assigned the role of responder. After all individuals had provided this information, the roles of proposer and responder were randomly assigned within each pair and the indicated offer (from the proposer) and the respective accept or reject decision (from the responder) were implemented. ${ }^{2}$ The corresponding payoff were paid in cash to each participant.

Our treatment variable in the experiment was the type of music played while individuals were making their decisions. As demonstrated by Bernardi et al. (2006), different musical styles can have different physiological effects in individuals. These effects, along with emotional responses, may result in different patterns of decision making regarding distributing money between oneself and another. In our Bon Scott treatment, participants listened to "It's a Long Way to the Top" (featuring Bon Scott on vocals) from the album High Voltage. In our Brian Johnson treatment, participants listened to "Shoot to Thrill" (featuring Brian Johnson on vocals) from the album Back in Black. These songs were chosen in order to avoid pre-conceived preferences for the band's biggest singles (e.g. "Highway to Hell," "You Shook Me All Night Long").

\section{Results}

A total of 36 participants from a large Canadian university took part in the experiment (two sessions of 18 individuals each). In one session, "It's a Long Way to the Top" was played while participants made their decisions; in the other session "Shoot to Thrill" was played while participants made their decisions. To maintain anonymity among subjects and bargaining pairs, participant pairings were made by computer and decisions were entered via computers located in separated experimental stations. ${ }^{3}$

To analyze the results, we compared the offers extended by participants across each treatment. For each participant we also calculated their minimum acceptable offer (MAO; representing the lowest offer a participant would accept) and compare these across treatments. Note that in any participant pair, an efficient outcome (i.e. an offer that was not rejected) was more likely in the presence of a higher offer and a lower MAO.

When the music of Bon Scott was played, participants extended offers (albeit in

\footnotetext{
${ }^{2}$ Oxoby and McLeish (2004) demonstrates that this manner of elicitation yields results that are indistinguishable from assigning roles prior to eliciting decisions.

${ }^{3}$ The experiments were programmed using the software by Fischbacher (1999).
} 
Canadian dollars) with mean (standard deviation) of 3.28 (1.18) whereas participants in the Brian Johnson treatment extended offers with mean (standard deviation) of 4 (0.97). The distributions of offers in each treatment are presented in Figure 4. Using nonparametric Wilcoxon rank-sum tests, we can reject the hypothesis that the distribution of offers across treatments are the same $(p=0.064)$. In terms of MAO, participants of Bon Scott treatment had minimum acceptable offers with mean (standard deviation) of 3.94 (0.87) while participants in the Brian Johnson treatment had minimum acceptable offers with mean (standard deviation) of 3.17 (1.25). The distributions of MAO are presented in Figure 4. Again, using nonparametric Wilcoxon rank-sum tests, we can reject the hypothesis that the distribution of MAO in each treatment are the same $(p=0.050)$. Thus, offers were lower and MAO were higher when participants heard the music of Bon Scott. This suggests that more offers would be rejected when listening to Bon Scott than when listening to Brian Johnson.

In terms of the actual number of pairs in which offers were rejected, we observed five rejections (four acceptances) in the Bon Scott treatment as opposed to three rejections (six acceptances) in the Brian Johnson treatment. As suggested by our analysis above, we observed a higher rate of rejection and hence less efficient outcomes when the music of Bon Scott was played during participants' decision-making.

\section{Conclusions}

The question as to who was a better singer, Bon Scott or Brian Johnson, may never truly be resolved. However, our analysis suggests that in terms of affecting efficient decision making among listeners, Brian Johnson was a better singer. Our analysis has direct implications for policy and organizational design: when policymakers or employers are engaging in negotiations (or setting up environments in which other parties will negotiate) and are interested in playing the music of $\mathrm{AC} / \mathrm{DC}$, they should choose from the band's Brian Johnson era discography.

\section{References}

Bernardi, L., Porta, C., and Sleight, P. (2006). Cardiovascular, cerebrovascular, and respiratory changes induced by different types of music in musicians and nonmusicians: the importance of silence. Heart, 92:445-452. 
Bolton, G. E. and Ockenfels, A. (2000). A theory of equity, reciprocity, and competition. American Economic Review, 30(1):166-193.

Camerer, C. F. (2003a). Behavioral Game Theory. Princeton University Press, Princeton NJ.

Camerer, C. F. (2003b). Strategizing in the brain. Science, 300:1673-1675.

Charness, G. and Rabin, M. (2002). Understanding social preferences with simple tests. Quarterly Journal of Economics, 117(3):817-869.

deQuervain, D. J.-F., Fischbacher, U., Treyer, V., Schellhammer, M., Schnyder, U., Buck, A., and Fehr, E. (2004). The neural basis of altruistic punishment. Science, 305:1254-1258.

Fehr, E. and Schmidt, K. (1999). A theory of fairness, competition, and cooperation. Quarterly Journal of Economics, 114(3):817-868.

Fischbacher, U. (1999). Toolbox for readymade economic experiments. Technical Report IEW Working paper 21, University of Zurich.

Oxoby, R. J. and McLeish, K. N. (2004). Specific decision and strategy vector methods in ultimatum bargaining: Evidence on the strength of other-regarding behavior. Economics Letters, 84(3):399-405.

Roth, A. E. (1995). Bargaining experiments. In Kagel, J. H. and Roth, A. E., editors, Handbook of Experimental Economics. Princeton University Press, New Jersey. 


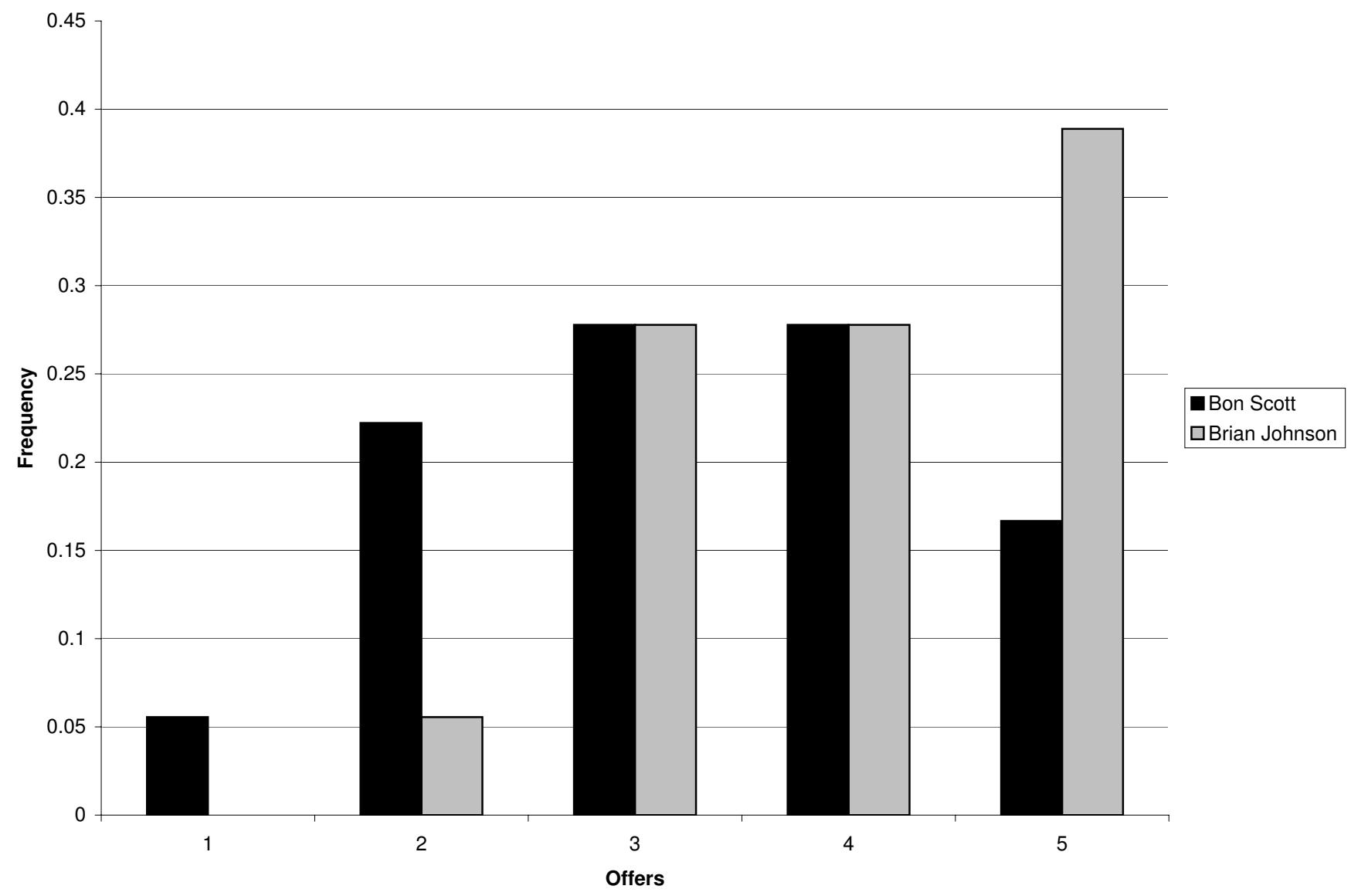

Figure 1: The distributions of offers in the Bon Scott and Brian Johnson treatments. 


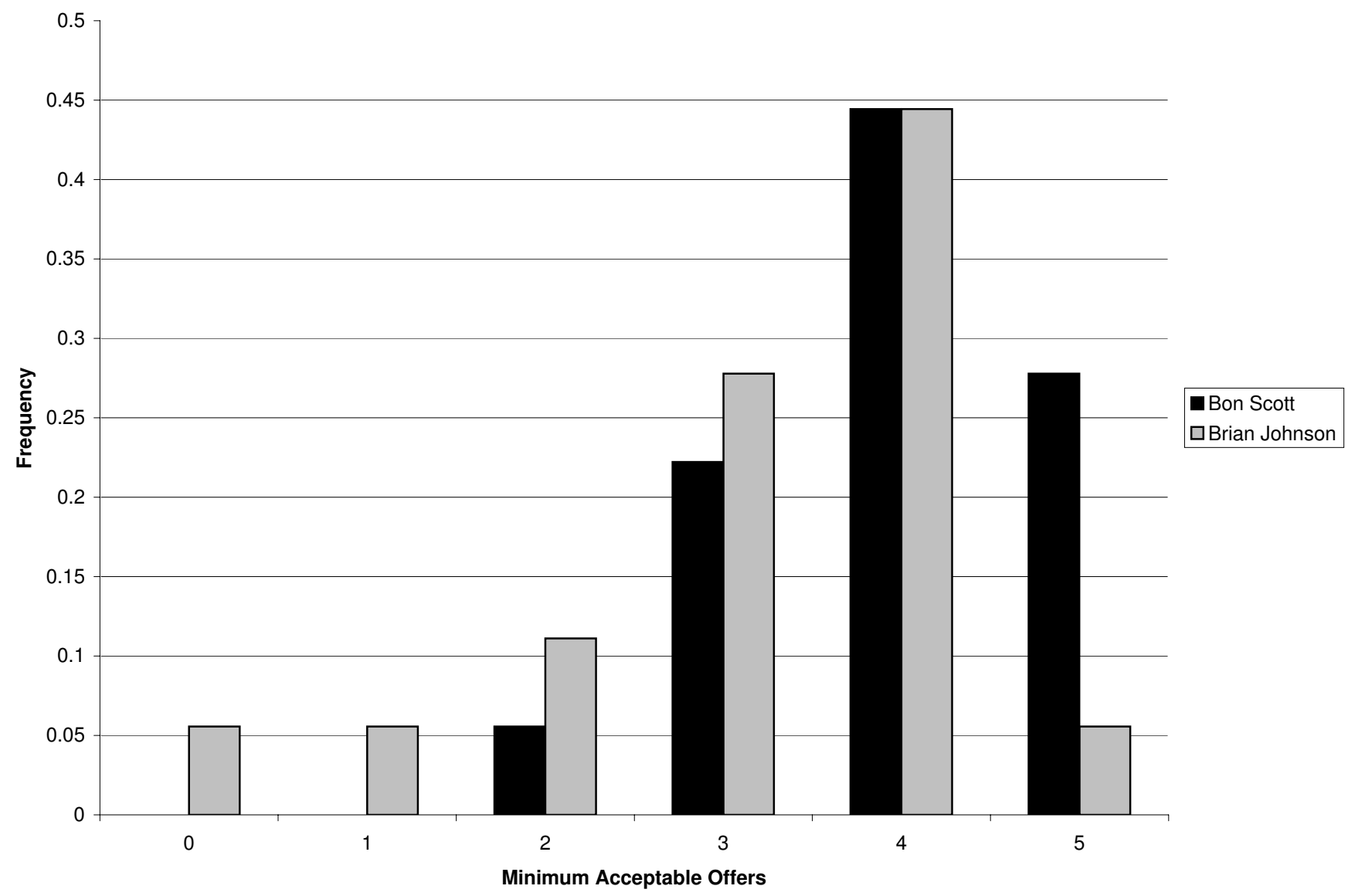

Figure 2: The distributions of MAO in the Bon Scott and Brian Johnson treatments. 